\title{
A formação na graduação dos profissionais de saúde e a educação para o cuidado de pacientes fora de recursos terapêuticos de cura
}

PALAVRAS-CHAVE

- Cuidados paliativos.

- Equipe de assistência ao paciente.

- Morte.
KEY WORDS

- Palliative care.

- Patient care team.

- Death.

\section{Undergraduate training in the health professions and education for care of patients beyond possibility of cure with available therapeutic resources}

Vera Anita Bifulco ${ }^{\mathrm{I}}$

Lúcia Christina Iochida ${ }^{\mathrm{I}}$

\begin{abstract}
R E S U M O
Este estudo trata de algumas questões fundamentais relacionadas com a filosofia dos Cuidados Paliativos (CP) e propõe uma educação dos alunos de graduação por meio de cursos de CP com o objetivo de criar uma atitude humanitária nos futuros profissionais em relação àquele que está morrendo. A esperança está na intervenção sobre a formação dos profissionais da saúde, na reformulação curricular que contemple esta visão antropológica, para além da formação tecnocientífica necessária, e na implementação da filosofia de CP. Buscaram-se na literatura discussões sobre a formação destes profissionais e o cuidado do paciente fora de recursos de cura, porém não fora de recursos sintomáticos. A metodologia adotada combina revisão da literatura nacional e internacional com pesquisa empírica, por meio da aplicação de questionário a uma equipe multiprofissional, atuante em CP numa instituição de ensino. O estudo foi desenvolvido com abordagem qualitativa. Desvelou-se na área da saúde a necessidade de capacitar os profissionais de saúde a enfrentaremo cuidado destes pacientes por meio de uma educação continuada, fundamentada no conhecimento do processo de morte e morrer.
\end{abstract}

\begin{abstract}
A B S T R A C T
The present study deals with some of the fundamental issues related to the philosophy of palliative care (PC) and specific undergraduate instruction by means of PC courses, aimed at establishing a humanitarian attitude by future health professionals towards patients facing death. Hope lies in impacting undergraduate training, curriculum reform that contemplates this anthropological vision (beyond the necessary technical and scientific training), and implementation of the PC philosophy. Aliterature search was conducted on the training of health professionals and care for patients that are beyond any possibility of cure, but still within the range of symptomatic treatment. The methodology combines a review of the national and international literature with empirical research, by applying a questionnaire to a multidisciplinary team working with PC in a teaching institution. The study used a qualitative approach and revealed the health field's need to train professionals to manage the care of these patients based on continuing education with knowledge about the process of death and dying.
\end{abstract}

Recebido em: 09/12/2007

Reencaminhado em: 03/09/2007

Aprovado em: 27/05/2008 


\section{INTRODUÇÃO}

A morte sempre foi e continuará a ser um grande desafio para os profissionais da área da saúde ${ }^{1}$. A diferença básica entre as pessoas em geral e os profissionais dessa área, como médicos, enfermeiros e psicólogos, é que, na vida destes, a morte faz parte do cotidiano e pode se tornar sua companheira de trabalho diária $^{2}$. Toda doença é uma ameaça à vida e, portanto, pode parecer um aceno à morte.

O século 20 assistiu à ascensão de uma medicina tecnológica e institucionalizada, capaz de prolongar a vida. Em decorrência deste avanço tecnológico e da disponibilidade de informação, a definição de morte vem sofrendo modificações que devem levar em conta os valores culturais da sociedade e não somente o conhecimento médico ${ }^{3}$.

Philippe Ariès (1977), historiador francês, escreveu duas obras fundamentais para o aprofundamento da questão do homem frente à morte. Em suas pesquisas, ele estuda a relação entre atitudes diante da morte, no que há de mais geral e comum, e no que concerne ao nosso destino individual e coletivo. São representações de morte que caracterizam atitudes do homem diante dela e são típicas de uma época ou momento histórico, embora algumas dessas manifestações possam ocorrer em qualquer tempo. Desde a morte domada, típica da época medieval, quando o homem conhecia a trajetória de sua morte, seja pelas guerras ou doenças. Era um evento público e social, e havia espaço para o sofrimento por meio inclusive dos rituais fúnebres. Até a morte invertida, interdita, a que não se fala, um evento solitário, oculto, combatido e visto como um fracasso. Ocorre, em sua maioria, nos hospitais, e o "poder" sobre a morte se transfere da religião para a medicina. As doenças se tornam crônicas, e o paciente "vive" morrendo. Mostra-se clara nessa evolução a necessidade de transformar esta morte interdita numa morte re-humanizada para os dias atuais ${ }^{4,5}$.

Ao refletirmos sobre tais questões, não podemos ignorar o fato de que não é a própria morte que desperta temor e terror, mas a imagem antecipada da morte, que hoje em dia vem revestida de isolamento, sofrimento e dor. Segundo Elias ${ }^{6}$, o terror e o temor são despertados somente pela imagem da morte na consciência dos vivos. Ainda segundo o autor, a tendência de isolar e ocultar a morte, tornando-a uma área especial, dificilmente terá diminuído desde o século 19, tendo possivelmente aumentado. Essas atitudes defensivas e o embaraço com que hoje as pessoas, muitas vezes, reagem a encontros com moribundos e com a morte são comparáveis às reações das pessoas a encontros abertos com aspectos da vida sexual na era vitoriana.
Uma das causas do despreparo dos profissionais para lidar com a morte, além dos aspectos cultural e espiritual pessoais, é que o ensino nos cursos da área da saúde enfatiza a formação técnico-científica dos futuros profissionais, propiciando pouco espaço para a abordagem dos aspectos emocionais, espirituais e sociais do ser humano. Nesse sentido, muitas vezes a morte pode ser relacionada com derrota, perda, frustração - o oposto da meta dos cursos da área da saúde, que é a cura ${ }^{7}$.

O modelo de atenção à saúde ensinado na graduação das escolas de Medicina e das demais profissões da área da saúde no Brasil se baseia em prevenção, diagnóstico, tratamento efetivo e cura de doenças. Entretanto, diante de uma situação de incurabilidade, esse modelo é ineficaz, o que nos leva a perguntar: o que fazer quando não há nada mais a ser feito para a cura desse paciente?

Esse questionamento levou à criação da Medicina Paliativa, que é o ramo da medicina responsável pelo cuidado total do paciente cuja doença é não responsiva ao tratamento curativo e que está vinculada aos Cuidados Paliativos (CP) - procedimentos feitos por todos os integrantes da equipe multiprofissional que trazem uma opção de tratamento adequado aos pacientes fora de recursos terapêuticos de cura, e de resgate da humanização da medicina.

O significado da palavra pallium, de origem greco-romana, está relacionado ao casaco de lã que era usado pelos pastores para enfrentar o clima adverso. Portanto, está relacionado com cuidado e proteção, não com medidas extraordinárias para combater a morte ${ }^{8}$.

$\mathrm{CP}$ constituem a quarta diretriz estabelecida pela Organização Mundial de Saúde (OMS) para o tratamento do câncer, depois de prevenção, diagnóstico e tratamento. Porém, no Brasil, esse item ainda é desconhecido pela maior parte dos pacientes e também por muitos profissionais da área da saúde ${ }^{9}$. McCoughla ${ }^{10}$ acrescenta à definição da OMS três elementos considerados fundamentais em CP: compaixão, humildade e honestidade.

Na ausência de possibilidade de cura, as doenças precisam ser "administradas" até o final de vida do paciente. O único enfoque médico disponível nesses casos é atenuar os sintomas, retardar e, quando possível, deter o rápido declínio físico e mental, ajudar o paciente a manter uma perspectiva positiva e evitar que a doença assuma o controle da sua vida ${ }^{11}$.

O movimento dos CP trouxe de volta, no século 20, a possibilidade de re-humanização do processo de morrer, opondo-se à idéia de morte como uma doença que deve ser curada custe o que custar. Ou seja, a morte é vista como parte de um processo da vida, e, no adoecimento, os tratamentos devem visar à qualidade dessa vida e ao bem-estar da pessoa, mesmo quando a cura 
não é possível. Mas frente a essa impossibilidade, nem sempre o prolongamento da vida é a melhor conduta, e isto não significa a prática da eutanásia. Segundo Figueiredo12, eutanásia é uma palavra de origem grega que, desmembrada, traduz-se em eu (bom) + thanatos (morte), ou seja, "boa morte", mas não é este o sentido a ela atribuído. Os profissionais de Cuidados Paliativos entendem que a solicitação de eutanásia é como um "pedido de socorro" por parte do paciente. Alguma de suas reais necessidades não estaria sendo atendida ${ }^{12}$.

Nos casos de comprometimento cognitivo dos pacientes, como nas demências ou estados vegetativos, na falta de um testamento ainda em vida, fica a cargo da família a deliberação das questões referentes ao fim da vida ${ }^{13}$.

A humanização compreende o alívio da dor e o controle dos sintomas que em CP devem começar desde o diagnóstico da doença crônica (oncológica ou não) até a fase avançada. Humanizar é atender às necessidades desse paciente. As equipes multiprofissionais de CP reúnem médicos, psicólogos, enfermeiros, assistentes sociais, fisioterapeutas, terapeutas ocupacionais e o serviço administrativo (recepção, triagem, segurança e transporte) - enfim, todos são importantes para confortar o paciente e responsáveis pelos seus cuidados.

A morte significa sempre um desafio para quem recebe treinamento para manter a vida ${ }^{14}$.

Entendemos que quanto mais cedo os alunos entrarem em contato com práticas humanitárias, maior a chance de despertarem para esta área mais adiante, quando forem profissionais. “Um curso teórico acrescenta. Um curso teórico-prático transforma. Eé de transformação que precisamos", ressalva Maciel ${ }^{15}$.

A esperança de que tenhamos profissionais mais sensíveis às necessidades da população e do indivíduo, que visem atender à pessoa doente mais que à doença, que se mobilizem numa assistência mais humanizada se concentra na academia, que deve estimular o ensino centrado na pessoa do paciente e na família. $\mathrm{Na}$ academia, o aluno vive um processo de aprendizagem no qual pode desenvolver atitudes de respeito e acolhimento, além de adquirir valores referentes à vida humana que, agregados ao conhecimento científico, vão subsidiar a prática humanizada ${ }^{16}$.

A aquisição destes valores seria proporcionada por um currículo que privilegiasse as competências inerentes a cada curso da área da saúde, assim como uma abordagem multiprofissional e a comunicação e a bioética como conteúdos imprescindíveis em todos os cursos, cobrindo todas as etapas do ciclo vital, inclusive a terminalidade e a morte. No Brasil, existem poucos cursos de Tanatologia destinados aos profissionais da saúde de maneira geral ${ }^{13,17,18}$.
Mas, se o tema morte é tão assustador e revestido de tanto preconceito, por que certos profissionais da área da saúde buscam exatamente cuidar de pacientes que vão morrer em breve, estando fora de recursos terapêuticos de cura? O que buscam ao se disporem a um contato mais próximo com pacientes à beira da morte? Em contraposição, que interesse esses pacientes despertam nos profissionais de $\mathrm{CP}$ que tanto os instiga a buscar um cuidar digno de quem está morrendo?

Considerando a hipótese, na medicina ocidental, de haver uma deficiência da formação acadêmica na preparação de profissionais da área da saúde para compreender melhor o processo de morte e morrer, o que vemos é um "olhar defeituoso" frente à morte de um paciente. Cada vez que o médico cura seu enfermo, é uma vitória contra sua própria morte. Quando a morte ganha a batalha, leva o doente e o médico. Emocionalmente, o profissional vê a morte de seu paciente como um fracasso, uma grande inimiga, uma derrota, talvez uma angústia frente a sua própria morte ${ }^{19}$.

Segundo Kubler-Ross (1969) apud Kóvacs ${ }^{20}$, é uma tarefa desafiante focalizar o paciente como pessoa e tratá-lo como ser humano, fazê-lo participar do tratamento. É difícil em nosso tempo encarar a morte como um fenômeno natural; ela é sempre atribuída a um fator externo. Com o avanço da ciência, mais se teme e se nega a morte como realidade.

Este estudo pretende contribuir para a prática de profissionais de saúde que cuidam de pacientes fora de possibilidades de cura, vivenciando sua terminalidade.

\section{OBJETIVOS}

A presente pesquisa teve como objetivo primeiro desvelar o tipo de formação em nível de graduação de profissionais que integraram a equipe multiprofissional de Cuidados Paliativos da Unifesp-EPM e sua possível repercussão sobre sua escolha profissional.

Como objetivos específicos, buscou: identificar a formação geral e específica do profissional da Unifesp-EPM que lida com a morte; desvelar as motivações que levaram os profissionais de saúde da Unifesp-EPM a participar de uma equipe de CP.

E, ainda, a partir da experiência da Unifesp-EPM, inferir a necessidade de intervenção nos cursos de graduação da área da saúde, para uma possível implementação do ensino dos CP.

\section{MÉTODO}

A presente pesquisa empregou uma abordagem qualitativa, que permite descrever, interpretar e se aproximar de uma compreensão maior da totalidade do ser humano, da sua unidade de vida como ser de liberdade e participação, responsável por suas 
vivências ${ }^{21}$. Permite ainda aprofundar os significados das ações e relações humanas (aspirações, crenças, valores e atitudes), diferentemente da pesquisa quantitativa, que procura, em tese, captar do fenômeno a região visível-concreta. A abordagem qualitativa permite também identificar o processo que a equipe de $\mathrm{CP}$ percorreu para atingir seu status atual de atuação profissional.

O estudo foi aprovado pelo Comitê de Ética em Pesquisa da Unifesp-EPM, sob o número de protocolo 0981/05. A amostra foi constituída por profissionais que atuaram na equipe multiprofissional de CP da Unifesp-EPM, pertencente à disciplina de Clínica Médica da EPM, de janeiro de 2001 a novembro de 2005. Antes da entrevista, todos os profissionais incluídos na pesquisa fizeram a leitura da Carta de Informação e assinaram o Termo de Consentimento Livre e Esclarecido.

Indiretamente, abordou-se a temática da educação para a morte, colocando em aberto a necessidade desta formação em nível de graduação.

Pela natureza deste estudo, considerou-se entrevistar não só a equipe fixa que atuava naquele momento, como também profissionais que tiveram um tempo significativo de permanência no grupo, mas não o integravam mais por não disporem de tempo. A decisão de incluir estes últimos profissionais foi baseada no fato de que os sete integrantes da equipe constituíam uma amostragem muito pequena para checar os objetivos desejados. Foram excluídos profissionais da saúde que não participaram da equipe multiprofissional de cuidados paliativos da Unifesp-EPM no período do estudo.

Citando Minayo ${ }^{22}$, a metodologia qualitativa analisa o fenômeno saúde/doença como um processo permeado de elementos culturais, sociais e econômicos, sendo compreendido e vivenciado diferentemente pelos vários atores que dele participam. Assim, o sucesso ou não de determinado serviço, ação ou programa também está relacionado a determinados valores, ideologias, posições de classe, status, crenças de seus usuários, comunidade e agentes.

Procurando uma base de entendimento para esta situação, em que o pesquisador conhece previamente o sujeito, encontrou-se respaldo em Schraiber ${ }^{23}$.

A escolha de questionário como instrumento de coleta de dados é referida como ferramenta desejável quando o propósito é coletar informações e quando existe um conjunto finito de questões a serem feitas e o pesquisador pode ser convencido da clareza e especificidade dos questionamentos ${ }^{24}$.

Após leitura minuciosa das respostas, foi realizada uma categorização das unidades de sentido, que, segundo Fernandes ${ }^{25}$, são expressões espontaneamente usadas pelos sujeitos para descrever o fenômeno que está sendo estudado. A análise e a interpretação dos significados apreendidos nos depoimentos escritos se mostraram suficientes para a compreensão do fenômeno deste estudo.

Para caracterizar a amostra, inicialmente foram realizadas análises descritivas dos dados. As variáveis qualitativas categóricas são apresentadas por meio de frequências absolutas (n) e de frequências relativas (percentuais). As variáveis quantitativas são apresentadas por médias, desvios-padrão e valores mínimo e máximo.

As análises estatísticas foram realizadas pelo programa computacional SPSS 10.0 for Windows (Statistical Package for Social Sciences, versão 10.0, 1999) ${ }^{26}$.

\section{RESULTADOS}

As respostas foram obtidas de outubro a novembro de 2005, mediante a entrega de questionário semiestruturado, com questões sociodemográficas e seis questões abertas.

\section{Análise quantitativa}

A amostra foi constituída por 15 profissionais da saúde de pacientes fora de recursos terapêuticos de cura, sendo $9(60 \%)$ do gênero feminino e 6 (40\%) do gênero masculino, 13 (86,7\%) da raça caucasiana. A média etária foi de 35,7 anos e desvio-padrão (DP) de 15,2. Aidade mínima foi de 22 anos, e a idade máxima de 80 anos, sendo a maior concentração na faixa etária de 20 a 40 $\operatorname{anos}(73,3 \%)$.

Os profissionais da saúde foram representados por dois assistentes sociais, um cirurgião-dentista, cinco enfermeiros, um fonoaudiólogo, três médicos, um nutricionista, um terapeuta ocupacional e um graduando em Fisioterapia.

A experiência profissional, verificada por meio do número de anos após a graduação, foi de 12,2 anos e DP de 15,4. O profissional com maior número de anos de profissão foi de 57 anos, e o de menor experiência ainda frequenta o curso de graduação. A porcentagem do tempo de experiência profissional dos profissionais de saúde foi: até 10 anos: 66,7\%; de 11 a 20 anos: 13,3\%; e 21 anos e mais: $20,0 \%$. Treze profissionais $(86,7 \%)$ já haviam concluído, pelo menos, curso de pós-graduação lato sensu.

A maioria já vivenciou experiência de perda, representada por 13 profissionais entrevistados $(86,7 \%)$, ao passo que 2 $(13,3 \%)$ não a vivenciaram.

O tempo decorrido desde a perda referida pelos profissionais foi de 15 dias ( 1 caso); 10 meses ( 1 caso); 1 ano ( 1 caso); 2 anos ( 2 casos); 4 anos (1 caso); 5 anos (1 caso); 6 anos ( 1 caso); 8 anos (1 caso); 10 anos ( 2 casos); 14 anos (1 caso) e 27 anos (1 caso).

As expectativas profissionais em relação ao trabalho com pacientes fora de recursos terapêuticos de cura foram citadas como 
"crescimento profissional" (3 profissionais); "carreira acadêmica e crescimento profissional" (1); "crescimento profissional e pessoal" (5); e "carreira acadêmica, crescimento profissional e pessoal" (6).

A temática da morte chegou ao conhecimento do profissional por "curso" (6 indivíduos); "palestra" (1); "reportagem" (1); "curso, palestra e reportagem" (1); "vivência profissional" (1); "leitura bibliográfica" (2); "curso, palestra e vivência profissional" (1); e "outros" (2).

Especificamente sobre a abordagem da temática morte nos cursos de graduação, observamos sua ausência na maioria dos cursos, pois $93,3 \%$ responderam que houve falta de formação para a morte.

\section{Análise qualitativa dos depoimentos}

Entre as manifestações do comportamento humano, a expressão verbal ou escrita e seus enunciados e mensagens podem ser vistos como indicadores indispensáveis à compreensão dos problemas ligados às práticas educativas e a seus componentes psicossociais. Fragmentos dos relatos escritos pelos sujeitos que participaram da pesquisa foram utilizados para ilustrar, apresentar e subsidiar as discussões e análise dos temas desenvolvidos.

Por meio do agrupamento das unidades de sentido, emergiram as categorias temáticas que se seguem descritas e exploradas.

\section{Vivência pessoal}

O paciente em sua terminalidade nos coloca frente a nossa própria finitude. Somente a experiência próxima com a morte desperta em nós a consciência da mortalidade. Só existe luto se houve vínculo.

Este contato com a própria finitude facilita o trabalho com todos os pacientes e não só com os "fora de recursos terapêuticos de cura". Na realidade, facilita o contato com todas as pessoas e com si própria.

Como enfermeiro intensivista, tenho muita experiência com a morte, mas pouca experiência com o processo de morte e com o estudo da morte. Com o grupo de Cuidados Paliativos e a presença de um grupo multiprofissional, estou tendo a oportunidade de aprender a trabalhar este processo, mudar de atitude e mudar o conceito, assim mudando o objetivo, cuidando das pessoas que estão fora de cura para uma morte melhor.

\section{A temática morte na formação acadêmica nos cursos de graduação}

A ausência da temática morte na formação acadêmica dos profissionais entrevistados foi sentida em sua totalidade.

A morte foi-lhes passada como um momento frio e solitário. O profissional da saúde se encontra despreparado para trabalhar com a morte, ele tem em sua formação o objetivo da cura. Quando um profissional da saúde perde um paciente, inconscientemente ele se depara com sua própria finitude ${ }^{13}$.

Desde a II Guerra Mundial, o progresso avassalador da ciência médica ocidental obscureceu a morte, excluindo-a do cenário clínico.

Não tive nenhuma formação curricular para a morte. Conheci o tema por outras vias. Sinto que tal formação é fundamental para a formação do médico (e de qualquer profissional de saúde).

Para os profissionais questionados, o processo de construção da identidade de paliativista é constituído pela aquisição de conhecimentos e habilidades técnicas específicas. Contudo, para alguns profissionais, o conhecimento técnico não é condição suficiente para a construção de uma identidade profissional.

\section{A vivência profissional em CP e seu efeito transformador na vida pessoal}

Alguns profissionais disseram que sua visão sobre os CP e a relação com a equipe foram profundamente transformadoras para suas vidas pessoais e profissionais na relação paciente/doença/morte.

Os Cuidados Paliativos permitem, a meu ver, intenso crescimento pessoal, uma vez que o contato real, sincero e realmente próximo, despido de preconceitos, com pacientes em contato com a morte leva a um crescimento pessoal pela quase obrigatoriedade do contato do profissional com o tema morte e com a questão da própria finitude. Este contato com a própria finitude facilita o trabalho com todos os pacientes e não só com os "fora de recursos terapêuticos de cura". Na realidade, facilita o contato com todas as pessoas e com si próprio.

É importante o profissional saber que existem doenças incuráveis, porém não doenças "intratáveis", e isso traz um crescimento pessoal e profissional, aprendendo a respeitar o outro como ser humano que é, ser social, que se emociona, que tem família, profissão, amigos. 
A assistência à totalidade do doente, extensiva à sua família, pressupõe tanto novas modalidades de relação entre os diversos membros da equipe, como uma nova forma de relação profissional de saúde/paciente ${ }^{27}$. Ainda segundo a autora, a incorporação da identidade de paliativista pelos profissionais de saúde inclui a transformação do seu olhar: não mais uma visão fragmentada da doença e de uma parte do corpo do doente, mas um olhar expandido para os novos domínios de intervenção: o social, o psicológico e o espiritual - em busca da "boa morte".

\section{DISCUSSÃO}

A grande maioria da população humana não dispõe de CP. Entre as barreiras para oferecer esses cuidados humanos e apropriados a pacientes terminais, destacam-se falhas na formação dos profissionais da área da saúde. Eles são treinados para curar e, quando isto não é factível, dizem que "não há mais nada que se possa fazer". Essa deficiência é considerada um dos principais obstáculos para oferecer CP adequados ${ }^{28}$.

Nossa sociedade atende pacientes segundo a realidade de cada instituição, contando com os recursos disponíveis em cada uma, às vezes insuficientes, quando existem. Na maioria das vezes, os pacientes tendem a procurar o serviço de saúde tardiamente, o que dificulta a cura ou a melhoria na sobrevida de milhões de pessoas e nos coloca frente aos $\mathrm{CP}$ como uma necessidade urgente e emergente em nossa sociedade.

Podemos afirmar que os CP são um direito do paciente e um dever dos profissionais de saúde e não meramente um luxo de países desenvolvidos. Devemos criar diretrizes nessa área e modelos adequados à realidade de nosso país. Morrer com dignidade é um direito de todo cidadão.

No atual estudo, a faixa etária dos profissionais revela que a motivação para participar de uma equipe de $\mathrm{CP}$, se aproximar do tema morte e vivenciar situações-limite entre a vida e a morte de pacientes independe da faixa etária. Temos desde uma estudante com 22 anos, ainda no término de sua graduação, até o chefe da equipe, com 80 anos. Essa motivação parece decorrer da falta do tema na graduação para a maioria dos profissionais questionados (93\% dos profissionais não tiveram nenhuma preparação acadêmica neste sentido) ou do despreparo desses profissionais para lidar com situações de morte por ausência dessa formação na graduação.

O tempo disponível de escuta do enfermo e família também se mostrou como atributo no processo de construção de identidade profissional.

A literatura revela que o treinamento dos profissionais de saúde, principalmente os de medicina, é voltado para curar doenças e, assim, aumentar a expectativa de vida da população. Mas quando o curar já nãoé mais possível, como fica esse profissional frente ao paciente fora de recursos terapêuticos curativos? Estará ele preparado para ver seu curar frustrado e seguir com tratamento somente sintomático?

O cuidado efetivo da dor e de outros sintomas que afligem o homem em sua terminalidade exige um programa abrangente, exemplificado na filosofia dos cuidados de hospice, como são conhecidos os CP. Os profissionais da saúde têm o dever de oferecer efetivo alívio da dor e dos sintomas da doença como contribuição poderosa para a qualidade de vida do paciente ${ }^{29}$, desde que este assim deseje, após ter sido adequadamente esclarecido sobre sua condição e os recursos disponíveis.

O avanço da ciência permitiu desenvolver tratamentos específicos, tornando possível controlar doenças que costumavam causar a morte, cronificando-se, ou, em alguns casos, propiciando a cura. O grande desafio para o profissional de saúde surge quando, ao perceber que a doença evoluiu a tal ponto que a cura não é mais possível, ele vê que a aproximação da morte de uma pessoa é inexorável e está além de quaisquer conhecimentos produzidos pelas ciências e tecnologias de intervenção.

São situações em que o profissional é provocado em sua capacidade de compreensão, tolerância e enfrentamento, tornando-se instrumento fundamental tanto no controle como no manejo da ansiedade do paciente. Daí a necessidade de instrumentalização e sensibilidade especial para lidar com a situação.

A pesquisa também revelou a significância da experiência próxima de morte, independentemente de esta ter ocorrido com pessoa de vínculo familiar. O paciente que está morrendo e do qual se cuidou durante tempo significativo para a formação de um vínculo afetivo também foi considerado. Somente dois profissionais não vivenciaram a morte dentro da família, mas a morte de seus pacientes os mobilizou para a importância do tema e da ação do cuidar específico quando a cura já não é mais possível.

As respostas também enfatizaram que tanto a formação como a vivência obtida por meio dos $\mathrm{CP}$ os fizeram entender elidar melhor com outros pacientes e não somente com os fora de recursos de cura, ampliando, assim, sua atuação profissional. Isto mostra a importância desta formação, que contribuiu para que os profissionais se tornassem seres humanos melhores, independentemente do foco do cuidar e da área específica de suas atuações. Como nossa sociedade cala o luto, cabe aos profissionais engajados no processo de re-humanização da morte abrir espaço para a expressão da dor e sofrimento, numa atmosfera acolhedora.

Parece que a humanização na área da saúde, segundo o que esta pesquisa pôde revelar, é mais um discurso de alguns grupos que acreditam que essa prática possa ser reveladora e ir ao encontro das necessidades de milhões de seres humanos em sua terminalidade. 
A questão educacional é imperativa na conscientização da comunidade e na reformulação das políticas públicas e currículos dos cursos voltados à formação de profissionais da saúde, porém ainda são poucas as universidades que realizam essa formação em nível de graduação.

A educação para lidar com a morte deveria ser um dos objetivos desses cursos, devendo ser entendida como um vasto campo de conhecimento que compreende o significado da morte, os processos de morrer, o pesar do luto, e envolve intencionalidade e planejamento, da mesma forma que outras disciplinas ou programas de saúde.

Se existe uma preocupação de que os estudantes tenham experiências de aprendizagem por meio de estágios nas diversas clínicas, nem sempre há intencionalidade durante os estágios para o cuidado com o paciente fora de possibilidades terapêuticas de cura. A existência na instituição de ensino de um serviço que oportunize estas experiências abre possibilidades para que os alunos tenham contato não somente com procedimentos que envolvem alta tecnologia, como os equipamentos e terapêutica de última geração, mas também com experiências com tecnologias mais simples, que envolvem atitudes como compaixão, respeito, diálogo, comunicação, e com terapêuticas de baixo custo, como o controle da dor e outros sintomas.

Nesse contexto, é preciso que o profissional da saúde, além do conhecimento adquirido, desenvolva a sensibilidade necessária, colocando os fundamentos humanitários de sua formação e de sua trajetória pessoal como indispensáveis à percepção e à contenção do sofrimento que vivenciam os pacientes em sua terminalidade.

Propomos disponibilizar aos futuros profissionais da saúde uma opção de mudança cultural e de comportamento, diagnosticar e tratar a enfermidade sem deixar de considerar o portador da mesma, tratar o ser humano e não somente a doença que o acomete.

A partir da experiência da Unifesp-EPM, consideramos interessante aprofundar o discurso de todos os que militam nesta área. Convidá-los a trocar suas experiências de como fazem CP conforme a singularidade de cada situação e provocar esse grupo para que elabore uma proposta de ensino na graduação que contemple os cuidados no fim da vida em todo o território nacional, obedecendo às peculiaridades socioculturais e econômicas de cada região brasileira.

Apesar das dificuldades existentes no serviço de CP da Unifesp-EPM, este representa uma experiência de ensino bem-sucedida, que alia a teoria à possibilidade de uma experiência prática e que estende o conhecimento à comunidade.

Acreditamos que todos os que já se desafiaram a trabalhar com CP têm um ponto em comum, somos todos nós eternos apaixonados pela vida e talvez por isso queiramos uma boa morte, para celebrar a vida vivida até então.

\section{CONCLUSÕES E RECOMENDAÇÕES}

A maioria dos profissionais de saúde da equipe de CP da Unifesp-EPM não teve na graduação qualquer formação para atender pacientes terminais. A formação desses profissionais foi predominantemente científica. Essa atitude cultural repassada ao estudante da área da saúde durante a graduação parece desprepará-lo para situações em que a cura já não é mais possível.

Essas constatações levam a inferir que os cursos de formação de profissionais de saúde carecem de disciplinas que abordem os temas da morte, do luto e do morrer, e, portanto, de disciplinas que conduzam esse profissional, para além do conhecimento técnico-científico adquirido, a desenvolver a sensibilidade necessária para praticar os fundamentos humanitários de sua formação, indispensáveis à percepção e ao lenitivo do sofrimento que vivenciam os pacientes em sua terminalidade. Uma assistência humanizada, que priorize a dignidade humana, também deve passar fazer parte do processo de aprendizado.

Conclui-se daí a necessidade de intervenção nos cursos de graduação da área da saúde e uma possível reformulação curricular que contemple uma visão antropológica para além da formação técnico-científica, com a implementação do ensino de $\mathrm{CP}$.

Uma mudança no currículo dos cursos de graduação, de forma que eles passem a incluir uma carga horária obrigatória para o estudo de $\mathrm{CP}$, poderia contribuir para aprimorar a formação humanística do profissional da saúde, prepará-lo para oferecer uma assistência digna que atenda às necessidades de portadores de doenças graves sem esperança de cura, de maneira a lhes proporcionar uma sobrevida com qualidade e levar a uma transformação positiva na relação entre o profissional de saúde e o paciente.

Outro de nossos objetivos era desvelar as motivações que levaram os profissionais de saúde da Unifesp-EPM a participar de uma equipe de CP. A pesquisa revelou que os profissionais se sentem motivados pelo assunto e atraídos pelos serviços existentes na área de $\mathrm{CP}$ por buscarem o conhecimento que lhes faltou na graduação.

Esse despreparo, enfatizamos, demonstra a necessidade urgente de uma mudança cultural na graduação dos profissionais da área da saúde, a exemplo do que acontece em países europeus, como a Inglaterra, berço dos CP, onde este ensino é dado na graduação médica e em estágios na residência médica.

No Brasil, alguns cursos de pós-graduação contemplam o estudo da morte e do morrer.

Considerando a universalidade do problema e pensando nos milhões de pessoas que morrem sem terem seu sofrimento atenuado e tratando-se de preocupação ainda lacunar no Brasil, 
resta-nos propor a extensão de estudos sobre o tema a outras instituições de ensino, e disseminar nossa experiência por meio de publicações e participação em eventos e palestras em instituições de ensino.

\section{REFERÊNCIAS}

1. Carvalho MVB, Perina EM. Cuidados paliativos pediátricos: a "essência do cuidar" da criança/adolescente/familiares nas situações limites. Mundo Saúde. 2003;27(1):93-7.

2. Kóvacs MJ. Profissionais de saúde diante da morte. In: Kóvacs MJ. Morte e Desenvolvimento Humano. São Paulo: Casa do Psicólogo; 1992. p.235-53.

3. Pazin Filho A. Morte considerações para a prática médica. Medicina (Ribeirão Preto); 2005. 38(1): 20-25, cap II. [Anais do Simpósio Medicina (Ribeirão Preto) Morte: Valores e Dimensões; Ribeirão Preto].

4. Ariès P Sobre a história da morte no Ocidente. Teorema: Lisboa; 1989.

5. Ariès P. O homem diante da morte. Rio de Janeiro: Francisco Alves; 1981. 2v.

6. Elias N. Capítulo 11. In: Elias N. A solidão dos moribundos: seguido de envelhecer e morrer. Rio de Janeiro: J. Zahar; 2001. p. 52-54.

7. Perdicaris AAM. A semiótica da morte e do morrer: um desafio à comunicação institucional. In: Rezende VL, (Org.). Reflexões sobre a vida e a morte: abordagem interdisciplinar do paciente terminal. Campinas: Ed UNICAMP; 2000. p.107-17.

8. Kovács MJ. Pacientes em estágio avançado da doença, a dor da perda e da morte. 2 ed. In: Carvalho MMJ, (Org.). Dor: um estudo multidisciplinar. São Paulo: Summus; 1999. p.318-37.

9. De Lima L, Bruera E. The Pan American Health Organization: its structure and role in the development of a palliative care program for Latin America and the Caribbean. J Pain Symptom Manage. 2000;20(6):440-8.

10. McCoughlan M. A necessidade de Cuidados Paliativos. Mundo Saúde. 2003;27(1):6-14.

11. Lown B. A Arte Perdida de Curar. São Paulo: JSN; 1997.

12. Figueiredo MTA. Eutanásia. In: Antonio Carlos Lopes (Ed.). Diagnóstico e Tratamento da SBCM. São Paulo: Manole; 2006. p.283-4.

13. Kóvacs MJ. Educação Para a Morte: Desafio na Formação de profissionais de Saúde e Educação. São Paulo: Casa do Psicólogo; 2003.
14. Silva MJP. Ancorando o aprendizado (estabelecendo bases). In: Silva MJP. O amor é o caminho (maneiras de cuidar). São Paulo: Loyola; 2006. p.21-31.

15. Maciel MGS. Cuidados Paliativos. No prelo 2007.

16. Rodrigues IG. Cuidados Paliativos: análise de conceito. Ribeirão Preto; 2004. Mestrado [Dissertação] - Universidade São Paulo, Escola de Enfermagem de Ribeirão Preto.

17. Figueiredo MTA. Educação em Cuidados Paliativos: uma experiência brasileira. Mundo Saúde 2003;27(1):165-70.

18. Instituto Sedes Sapientiae. Cursos do instituto Sedes, 2006. [homepage na Internet]. São Paulo: Sedes [Acesso em 25 fev. 2006]. Disponível em: <http:/ / www.sedes.org.br>.

19. Bifulco VA. Princípios éticos e humanitários no cuidado de pacientes graves. Revista Meio de Cultura. 2004;25:19-20.

20. Kóvacs MJ. Paciente terminal e a questão da morte. In: Kóvacs MJ. Morte e Desenvolvimento Humano. São Paulo: Casa do Psicólogo; 1992. p.195-201.

21. Carvalho MVB. O cuidar no processo de morrer na percepção das mulheres com câncer. São Paulo; 2003. Doutorado [Tese]-Universidade deSão Paulo, Escola de Enfermagem.

22. Minayo MC. O Desafio do Conhecimento: pesquisa qualitativa em Saúde. Rio de Janeiro: Abrasco; 1992.

23. Schraiber LB. Pesquisa qualitativa em saúde: reflexões metodológicas do relato oral e produção de narrativas em estudo sobre a profissão médica. Rev Saúde Pública. 1995; 29(1):63-74.

24. Grey M. Métodos de Coleta de Dados. In: Lobiondo-Wood G, Haber J. Pesquisa em Enfermagem: métodos, avaliação crítica e utilização. Rio de Janeiro: Guanabara Koogan; 2001. p.174-85.

25. Fernandes MFP. Conflitos éticos da enfermeira: uma abordagem heideggeriana. São Paulo; 1998. Doutorado [Tese] Universidade de São Paulo, Escola de Enfermagem.

26. The SPSS Statistical package for the social sciences: base user's guide [computer program]. Version 10.0. Chicago: SPSS; 1999.

27. Menezes RA. Em Busca da boa morte: antropologia dos cuidados paliativos. Rio de Janeiro: Ed. Fiocruz; 2004.

28. Brandão C. Nova realidade. Revista ABCâncer. 2005;5(27):18-19.

29. Pessini L, Bertachini L. Humanização e Cuidados Paliativos. São Paulo: EDUNISC; Loyola; 2004. 


\section{CONFLITO DE INTERESSES}

Declarou não haver.

\section{ENDEREÇO PARA CORRESPONDÊNCIA}

Vera Anita Bifulco

Av. Senador Casimiro da Rocha, 809 - apto 142

\section{Mirandópolis}

CEP.: 04047-002 São Paulo - SP

E-mail: vbifulco@uol.com.br 